\title{
Translocation of phospho-protein kinase Cs implies their roles in meiotic-spindle organization, polar-body emission and nuclear activity in mouse eggs
}

\author{
Zhen-Yu Zheng ${ }^{1,2}$, Qing-Zhang Li ${ }^{2}$, Da-Yuan Chen ${ }^{1}$, Heide Schatten ${ }^{3}$ and Qing-Yuan Sun ${ }^{1}$ \\ ${ }^{1}$ State Key Laboratory of Reproductive Biology, Institute of Zoology, Chinese Academy of Sciences, Beijing \\ 100080, People's Republic of China, ${ }^{2}$ College of Life Sciences, Northeast Agricultural University, Harbin 150030, \\ People's Republic of China and ${ }^{3}$ Department of Veterinary Pathobiology, University of Missouri-Columbia, \\ Columbia, MO 65211, USA
}

Correspondence should be addressed to Q-Y Sun; Email: sunqy1@yahoo.com

\begin{abstract}
The protein kinase Cs (PKCs) are a family of Ser/Thr protein kinases categorized into three subfamilies: classical, novel, and atypical. The phosphorylation of PKC in germ cells is not well defined. In this study, we described the subcellular localization of phopho-PKC in the process of mouse oocyte maturation, fertilization, and early embryonic mitosis. Confocal microscopy revealed that phospho-PKC (pan) was distributed abundantly in the nucleus at the germinal vesicle stage. After germinal vesicle breakdown, phospho-PKC was localized in the vicinity of the condensed chromosomes, distributed in the whole meiotic spindle, and concentrated at the spindle poles. After metaphase I, phospho-PKC was translocated gradually to the spindle mid-zone during emission of the first polar body. After sperm penetration and electrical activation, the distribution of phospho-PKC was moved from the spindle poles to the spindle mid-zone. After the extrusion of the second polar body (PB2) phospho-PKC was localized in the area between the oocyte and the PB2. In fertilized eggs, phospho-PKC was concentrated in the pronuclei except for the nucleolus. Phospho-PKC was dispersed after pronuclear envelope breakdown, but distributed on the entire spindle at mitotic metaphase. The results suggest that PKC activation may play important roles in regulating spindle organization and stabilization, polar-body extrusion, and nuclear activity during mouse oocyte meiosis, fertilization, and early embryonic mitosis.
\end{abstract}

Reproduction (2005) 129 229-234

\section{Introduction}

Protein phosphorylation is considered one of the most versatile posttranslational modifications in eukaryotic cells. Protein kinases represent key molecules in a variety of signaling mechanisms capable of delivering information from the cell surface to the nucleus. One of the most important enzyme families is the protein kinase $C$ (PKC) family. The PKC family consists of 11 different serine/threonine kinases that are subdivided into three groups based on sequence homology, as well as on activator and cofactor requirements. These groups include the conventional $(\mathrm{PKC} \alpha, \beta \mathrm{I}, \beta \mathrm{II}$, and $\gamma$ ), novel (PKC $\delta, \varepsilon, \theta, \mu$, and $\eta)$, and atypical (PKC $\lambda / \tau$ and $\zeta$ ) isoforms (Mellor \& Parker 1998, Viveiros et al. 2003). The conventional PKC isotypes are activated by $\mathrm{Ca}^{2+}$ and diacylglycerol. The novel PKCs are $\mathrm{Ca}^{2+}$-insensitive, but are still activated by diacylglycerol. The atypical PKCs are neither $\mathrm{Ca}^{2+}$ - sensitive, nor do they respond to diacylglycerol (Mellor \& Parker 1998, Ventura \& Maioli 2001). Activated PKCs can translocate to the nucleus where they phosphorylate a number of protein transcription regulators in a cell-cycle-dependent manner or in response to cell stimulation for exit from quiescence $\left(\mathrm{G}_{0} \rightarrow \mathrm{G}_{1}\right.$ transition; Boulikas 1995).

In mammalian ovary, the oocyte is arrested at the diplotene stage of the first meiosis until sexual maturity. In each cycle, limited numbers of oocytes initiate meiosis, as indicated by the germinal vesicle (GV) breakdown (GVBD), and then they organize the meiotic spindle and extrude the first polar body, leading to the production of mature, fertilizable oocytes (Voronina \& Wessel 2003). Fertilization initiates a rapid series of changes that restructure the egg into the zygote and initiate the program of early development. These changes are mediated by a series of cytoplasmic signal transduction events initiated by the rise in intracellular $\left[\mathrm{Ca}^{2+}\right]_{i}$. PKCs appear to have multiple functional roles in the cell-cycle progression during oocyte maturation (Downs et al. 2001, Quan et al. 2003). Stimulation of PKC is a sufficient and necessary event to 
induce meiosis resumption during maturation of cumulusenclosed mouse oocytes, but blocks meiosis resumption in cumulus-free oocytes (Sun et al. 1999, Downs et al. 2001, Quan et al. 2003). Prolonged activation of PKC arrests mouse oocytes at the first metaphase (MI) stage and blocks polar-body emission (Bornslaeger et al. 1986, LeFevre et al. 1992, Quan et al. 2003), while suppression of PKC promotes the onset of anaphase I (Viveiros et al. 2004). During fertilization, the mechanism by which a transient calcium burst triggers maturation promoting factor (MPF) inactivation involves a PKC-dependent pathway and activation of PKC is required for remodeling of the egg into the zygote (Colonna et al. 1997, Gallicano et al. 1997, Eliyahu \& Shalgi 2002, Fan \& Sun 2004).

Different PKC isoforms have been identified in mouse, rat and pig oocytes (Gangeswaran \& Jones 1997, Raz et al. 1998, Fan et al. 2002). Conventional PKC $\alpha, \beta \mathrm{I}, \beta \mathrm{II}$, and $\gamma$, novel PKC $\delta$, and atypical $\operatorname{PKC} \lambda, \mu$, and $\xi$ were found to exist in mouse oocytes and their subcellular localization was in a stage-dependent fashion during oocyte maturation and early development (Gangeswaran \& Jones 1997, Luria et al. 2000, Page Pauken \& Capco 2000). More recently, the specific function of PKC isoforms in oocyte was studied. It was found that the inhibition of GVBD of cumulus-free mouse oocytes was dependent on not only conventional PKC isoforms, but also other PKC isoforms (Quan et al. 2003). PKC $\delta$ was found to be associated with meiotic spindle and then with the chromosomes at the metaphase II (MII) stage in LTXBO strain mouse oocytes. PKC $\delta$ also participated in the regulatory mechanisms that delay the oocyte's entry into anaphase I. Its disruption promoted untimely entry into the interphase. Thus, loss of regulatory control over PKC activity during oocyte maturation disrupts the critical MI-MII transition, leading to a precocious exit from meiosis (Viveiros et al. 2001). PKC $\delta$ was also found to dephosphorylate after fertilization of mouse oocytes (Viveiros et al. 2003). However, the role of PKC phosphorylation in oocyte maturation and fertilization is largely unknown.

In this study, we characterized the subcellular distribution profile of phopho-PKC (pan) during the progression of mouse oocyte meiosis, egg activation, and early embryo cleavage with an antibody which recognizes phosphorylated isoforms of PKC $\alpha, \beta \mathrm{I}, \beta \mathrm{II}, \gamma, \delta, \varepsilon, \zeta, \eta$, and $\theta$ using immunofluorescent confocal analysis.

\section{Materials and Methods}

\section{Oocyte isolation and culture}

All mice were bred and raised in the animal research colony of the State Key Laboratory of Reproductive Biology, Chinese Academy of Sciences, Beijing, People's Republic of China. GV-stage oocytes were recovered from ovaries of 4-6-week-old Kunming mice $48 \mathrm{~h}$ after the females were injected with $10 \mathrm{IU}$ pregnant mare's serum gonadotropin (PMSG). Cumulus-free and GV-intact oocytes were cultured in $\mathrm{M} 2$ medium at $37^{\circ} \mathrm{C}$ in an incubation chamber equilibrated with $5 \% \mathrm{CO}_{2} / 5 \% \mathrm{O}_{2} / 90 \% \mathrm{~N}_{2}$. The oocytes were collected following $0,2,8,10$, and $12 \mathrm{~h}$ of culture for confocal microscopy. Progression to MII was indicated by the presence of the first polar body.

\section{Electrical activation and fertilization of oocytes}

Mice were treated with PMSG, followed by $10 \mathrm{IU}$ human chorionic gonadotropin (hCG) approximately $48 \mathrm{~h}$ later. MII-stage eggs were recovered from the oviduct ampullae $15 \mathrm{~h}$ after hCG treatment and the surrounding cumulus cells were removed by a brief exposure to $300 \mathrm{IU} / \mathrm{ml}$ hyaluronidase (Sigma) in M2 medium. The denuded eggs were washed three times in electro-portion medium $(0.25 \mathrm{M}$ sorbic alcohol, $0.1 \mathrm{mM}$ calcium acetate $\left(\left(\mathrm{CH}_{3} \mathrm{COO}\right)_{2} \mathrm{Ca}\right)$ $0.5 \mathrm{mM}$ magnesium acetate $\left(\left(\mathrm{CH}_{3} \mathrm{COO}\right)_{2} \mathrm{Mg}\right.$ and $0.5 \mathrm{mM}$ Hepes) and were put in a fusion chamber, with two wires of $1 \mathrm{~mm}$ apart then a $10-\mu \mathrm{s}$ pulse at $180 \mathrm{v} / \mathrm{mm}$ was exerted. The eggs were washed three times and incubated in $\mathrm{M} 16$ medium at $37^{\circ} \mathrm{C}$ for an additional $6-8 \mathrm{~h}$ to evaluate pronucleus formation. A second group of MII eggs recovered from the oviduct was fertilized in vitro. The cauda epididymal spermatozoa were capacitated in M16 medium at $37^{\circ} \mathrm{C}$ in a humidified modular $\mathrm{CO}_{2}$ incubation chamber for $1 \mathrm{~h}$, then zona pellucida-free eggs were inseminated with capacitated spermatozoa $\left(1 \times 10^{6}\right.$ cells $\left./ \mathrm{ml}\right)$ in a $50 \mu \mathrm{l}$ drop of M16 medium. The emission of the second polar body and the formation of the pronuclei were observed with an inverted microscope. The eggs were collected at $10 \mathrm{~min}, 30 \mathrm{~min}, 2 \mathrm{~h}$, and $8 \mathrm{~h}$ after an electrical pulse and at 1,2 , and $8 \mathrm{~h}$ after insemination for confocal microscopy analysis.

For in vivo fertilization, the females were superovulated with $10 \mathrm{IU}$ PMSG and 10IU hCG, separated by an $48 \mathrm{~h}$ interval, and mated with the same strain of males. The zygotes were collected from the oviduct ampullae of superovulated females $16 \mathrm{~h}$ after hCG administration. After removing cumulus cells with $300 \mathrm{IU} / \mathrm{ml}$ hyaluronidase in M2 medium, zygotes were cultured in M16 medium at $37^{\circ} \mathrm{C}$ in a humidified atmosphere of $5 \% \mathrm{CO}_{2}$. The early embryos were collected at $6,12,18$, and $24 \mathrm{~h}$ of culture for confocal microscopy analysis.

\section{Immunofluorescence}

A total of approximately 30 oocytes, eggs, or embryos in three replicates were collected at each time point of in vitro maturation, fertilization, and early embryo development. Evidently degenerated and untimely developed eggs were excluded from the analysis. The zona pellucida was removed by a short exposure of the oocytes, eggs, or early embryos to acid $\mathrm{M} 2$ medium $(\mathrm{pH} 2.5)$, and fixed with $4 \%$ paraformaldehyde in $\mathrm{PBS}(\mathrm{pH} 7.4)$ for at least $30 \mathrm{~min}$ at room temperature. Cells were permeabilized with incubation buffer $(0.5 \%$ Triton- 100 in $20 \mathrm{mM}$ Hepes, $\mathrm{pH} 7.4,3 \mathrm{mM} \mathrm{MgCl} 2,50 \mathrm{mM} \mathrm{NaCl}, 300 \mathrm{mM}$ sucrose and $0.02 \% \mathrm{NaN}_{3}$ ) for $30 \mathrm{~min}$ at $37^{\circ} \mathrm{C}$ in a incubation chamber, 
followed by blocking in 1\% BSA for $1 \mathrm{~h}$ and incubation overnight at $4^{\circ} \mathrm{C}$ with polyclonal rabbit anti-phospho-PKC (pan) antibody (Cell Signaling Technology, Beverly, MA, USA; gamma Thr-514, catalog no. 9379S) diluted 1:100 in blocking solution. After three washes in PBS containing $0.1 \%$ BSA, $0.1 \%$ Tween-20, and $0.01 \%$ Triton-100 for 5 min each, the eggs were incubated with FITC-conjugated goat anti-rabbit IgG (Jackson Immunoresearch Laboratories, West Grove, PA, USA) diluted 1:100 for $1 \mathrm{~h}$. Following three washes, the nuclear status of oocytes was evaluated by staining with $10 \mu \mathrm{g} / \mathrm{ml}$ propidium iodide in PBS for $10 \mathrm{~min}$. Oocytes/eggs that were labeled only with the second antibody were used as negative controls. Following extensive washing, samples were mounted between a coverslip and a glass slide supported by four columns of a mixture of vaseline and paraffin (9:1). The slides were sealed with nail polish. Each experiment was repeated three times. Cells were observed under a Leica confocal laser scanning microscope (TCS-4D).

\section{Results}

\section{Subcellular localization of phospho-PKC during meiotic maturation}

In GV oocytes freshly released from the follicles, phosphoPKC was localized to the entire GV except for the nucleolus (Fig. 1A). When GVBD just occurred, phospho-PKC was distributed throughout the original GV area (Fig. 1B). Then, phospho-PKC condensed to numerous dots and was distributed around the condensed chromosomes (Fig. 1C); phospho-PKC staining moved to the opposite two sides of the chromosomes (Fig. 1D). It was distributed in the whole meiotic spindle but mainly localized to the meiotic-spindle poles at $\mathrm{MI}$ (Fig. 1E). During the transition from anaphase I to telophase I, following the separation of homologous chromosomes, phospho-PKC was translocated from the spindle poles to the midbody (Fig. $1 \mathrm{~F}$ and G). Immediately after meiosis I, the oocytes entered meiosis II without interphase. The distribution pattern of phospho-PKC in MII oocytes was the same as that in MI oocytes (Fig. 1H). In oocytes that failed to undergo GVBD after maturation culture, phospho-PKC was still localized to the GV (Fig. 1I). In the negative control, oocytes that were treated only with the second antibody on staining were observed (results not shown).

\section{Subcellular localization of phospho-PKC during electrical activation and in vitro fertilization of eggs}

During in vitro fertilization, phospho-PKC was translocated from the spindle poles to the mid-zone (Fig. 2A and B). The eggs extruded their second polar body about $2 \mathrm{~h}$ after insemination, and phospho-PKC was localized between the separated oocyte and the second polar body (Fig. 2C). After formation of pronuclei $6-8 \mathrm{~h}$ following
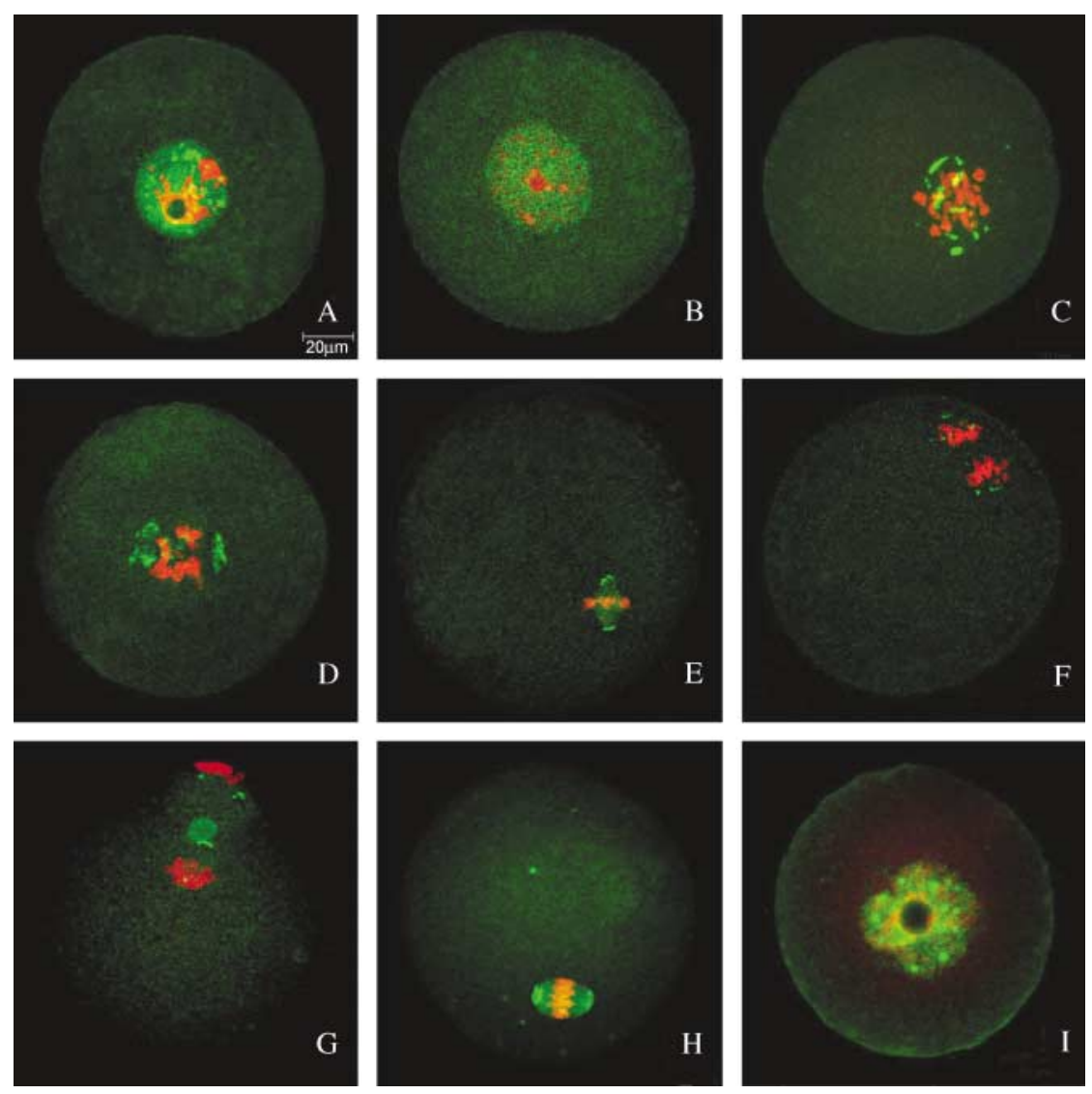

Figure 1 Immunofluorescent localization of phospho-PKC during meiotic maturation of mouse oocytes. Green, phospho-PKC; red, chromatin. During oocyte maturation, phospho-PKC gradually translocated from the GV area (A) to the condensed chromosomes $(\mathrm{B}, \mathrm{C})$, and finally moved to the organizing spindle poles $(D, E)$. During the anaphase I-telophase I transition phospho-PKC was translocated from the middle poles to the middle plate of spindle (G). Phospho-PKC was present in the entire MII spindle, but mainly localized to the spindle poles at the MII stage $(\mathrm{H})$. In the oocytes that failed to undergo GVBD after culture, phospho-PKC was still present in the GV (I). 

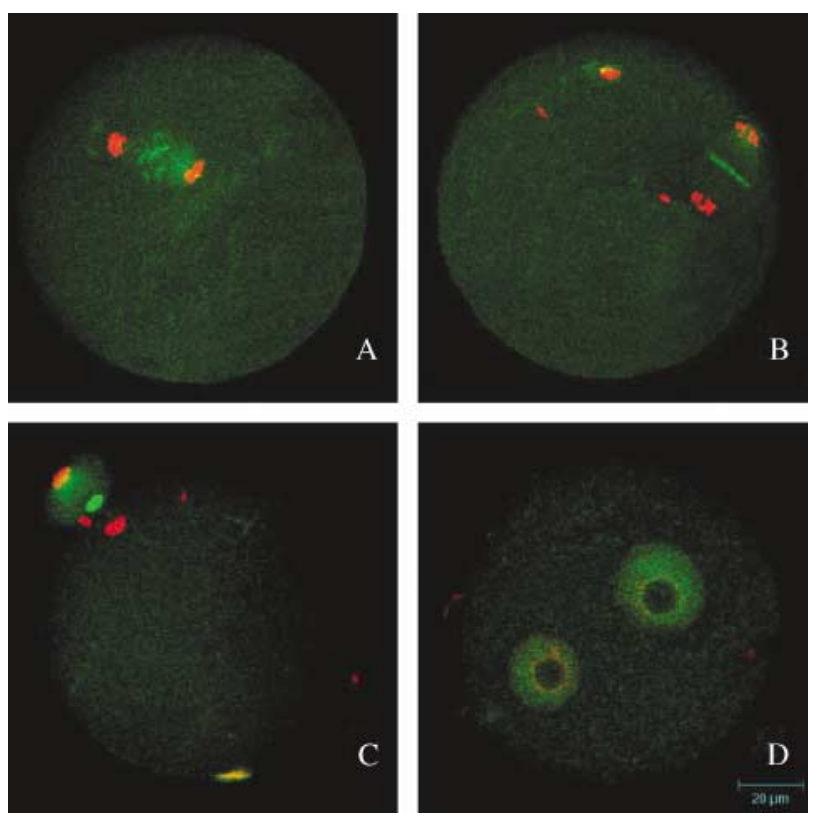

Figure 2 Subcellular localization of phospho-PKC during in vitro fertilization. During in vitro fertilization, phospho-PKC was translocated from the spindle poles (A) to the mid-zone at late anaphase (B) and telophase (C). In the pronuclear phase, phospho-PKC was distributed in the pronucleoli except the pronucleoli (D).

insemination, phospho-PKC was evenly localized to the pronuclei except for the pronucleoli (Fig. 2D). After electrical activation, phospho-PKC showed a similar distribution pattern to in vitro-fertilized eggs (Fig. 3).

\section{Subcellular localization of phospho-PKC during early cleavage}

In in vivo-fertilized eggs, phospho-PKC was concentrated in the pronuclei (Fig. 4A). When the zygotes underwent nuclear-envelope breakdown, phospho-PKC was distributed in the entire cytoplasm (Fig. 4B and C). At metaphase
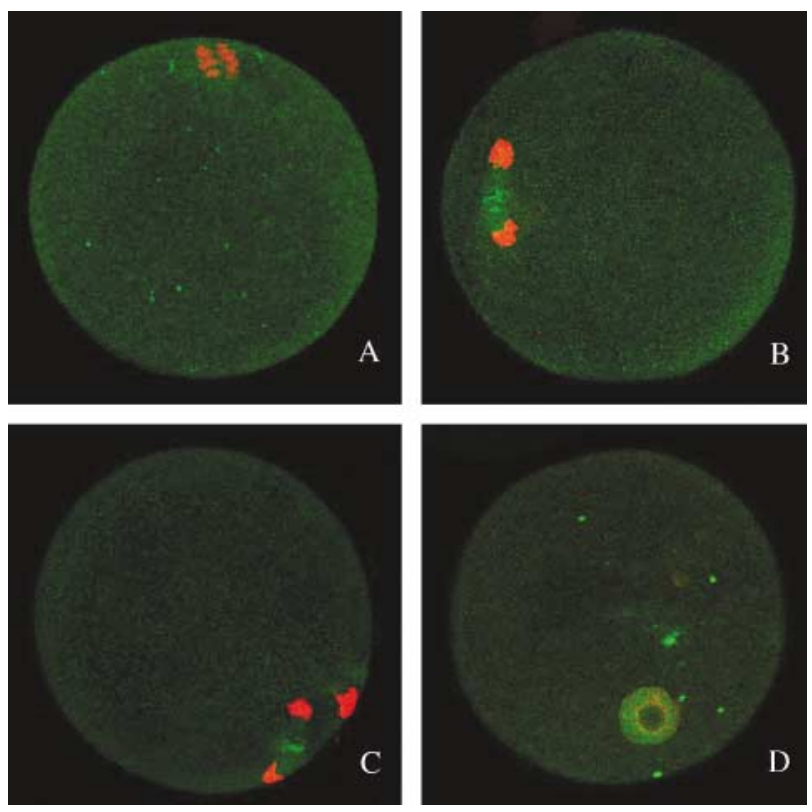

Figure 3 After electrical activation, phospho-PKC moved from the spindle poles at early anaphase (A) to the middle plate of the spindle at late anaphase (B), and finally concentrated to the midbody at telophase (C). Evident staining was observed in the pronuclei except for the nucleolus (D).

of the first mitosis, phospho-PKC was distributed in the whole mitotic spindle, with a more-concentrated localization at the spindle poles (Fig. 4D). In the two-cell stage, phospho-PKC showed a similar distribution pattern as in the one-cell stage (Fig. 4E and F).

\section{Discussion}

Anti-phospho-PKC (pan) detects endogenous levels of PKC $\alpha, \beta I, \beta I I, \gamma, \delta, \varepsilon, \zeta, \eta$, and $\theta$ that are phosphorylated at a C-terminal residue homologous to the residue Thr-514 of human PKC $\gamma$, as illustrated in the Cell Signaling
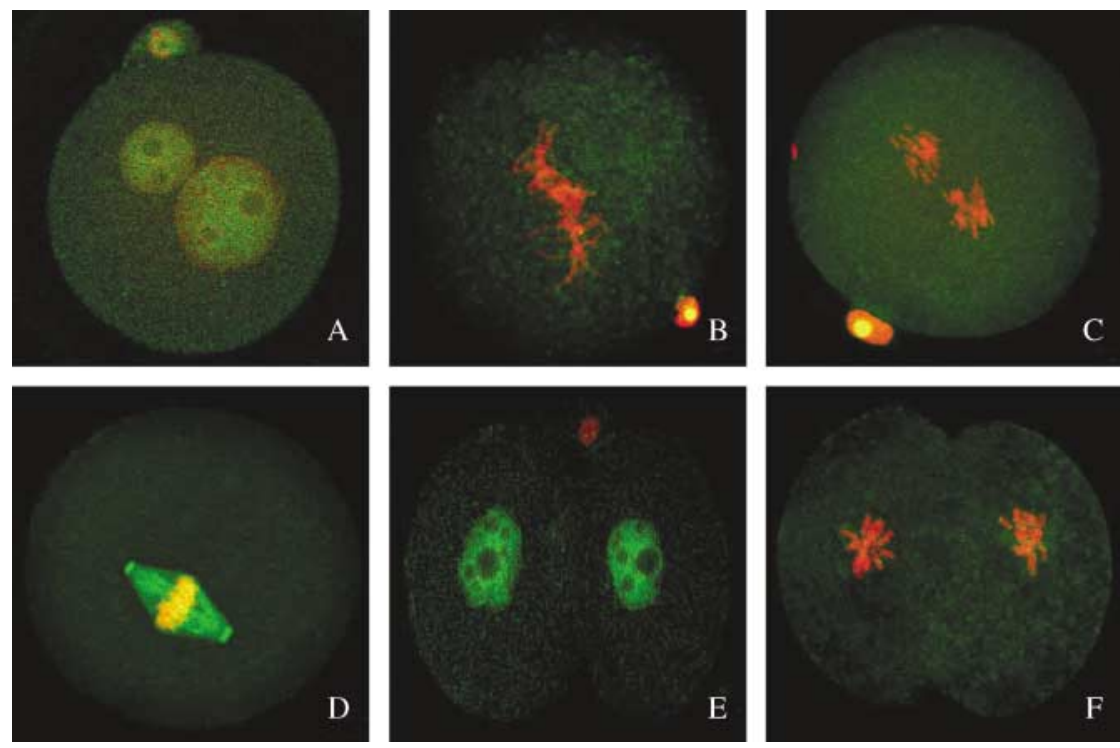

Figure 4 Subcellular localization of phosphoPKC during in vivo fertilization and early cleavage. In the pronuclear phase, phosphoPKC was localized to the pronuclei except in the nucleolus (A), but distributed evenly in the cytoplasm after nuclear-envelope breakdown (B, C). Phospho-PKC was distributed across the whole mitotic spindle and mainly localized to the spindle poles during the first cleavage (D). In the two-cell stage, phosphoPKC showed a similar distribution pattern as in first cleavage $(E, F)$. 
Technology product catalog. In the current study, by using this antibody, we characterized the localization of phospho-PKC, aiming to provide evidence for the involvement of PKC phosphorylation in various stages of mouse oocyte meiotic maturation, fertilization, and early mitotic division. It should be remembered that this antibody recognizes 9 of the 11 isoforms of PKC but that it it does not detect PKC phosphorylated at other residues. In addition, this antibody is not isoform-specific, and thus the analysis of the exact role of specific PKC isoform is limited.

In mouse GV oocytes, PKC $\alpha, P K C \beta I I$, and RACK1 (receptor for activated $C$ kinase 1) were uniformly distributed in the cytoplasm, while PKC $\beta I$ was localized in the cytoplasm and in the plasma membrane as well (Luria et al. 2000). A recent study revealed diffuse expression of PKC $\delta$ throughout the cytoplasm and nucleus of GV-stage oocytes (Viveiros et al. 2003). In contrast, we found that phospho-PKC was concentrated in the entire GV except for the nucleolus. Previous reports by others and us indicated that PKC activation inhibited the meiotic resumption of cumulus-free mouse oocytes and this effect could be overcome by PKC inhibitors (LeFevre et al. 1992, Sun et al. 1999, Luria et al. 2000, Quan et al. 2003). Our present results, together with previous reports, provide evidence showing that PKC phosphorylation may be involved in GVBD regulation, but how PKC phosphorylation regulates GVBD needs further clarification.

Shortly after GVBD, phospho-PKC condensed and distributed around the condensed chromatin from which microtubules radiate. Phospho-PKC was distributed in the whole meiotic spindle and mainly localized to the meiotic-spindle poles at $\mathrm{MI}$, but translocated to the spindle middle plate at the anaphase I-telophase I transition, following the separation of homologous chromosomes. Similar phosho-PKC translocation was also observed after sperm penetration or parthenogenetic activation of MII oocytes. By using the LTXBO mouse oocytes which are arrested at the MI stage, Viveiros et al. (2001) proposed a hypothesis that PKC participates in the meiosis I-meiosis II transition. Our previous study also showed that PKC activation after GVBD leaded to the inhibition of mitogenactivated protein kinase phosphorylation and arrested the cell cycle at the MI stage (Quan et al. 2003). It was reported recently that during meiotic maturation phosphorylated PKC $\delta$ was distinctly associated with the spindle apparatus during the first meiotic division, while it was dephosphorylated following completion of meiosis II after fertilization (Viveiros et al. 2003). By using normal oocytes isolated from small antral follicles, which have not yet developed the capacity to progress to MII, and also oocytes defective in their ability to exit MI, this group also reported that transient suppression of endogenous PKC activity by treatment with a PKC-specific inhibitor promoted the onset of anaphase I in a dose-dependent manner (Viveiros et al. 2004). Another recent report indicated that many isotypes of PKC were enriched around the meiotic spindle and that $\mathrm{PKC} \zeta$ is involved in spindle stability (Page Baluch et al. 2004). In different mitotic cells, various PKC isoforms were found to associate with the mitotic apparatus and colocalize with $\beta$-tubulin in spindle microtubules (Lehrich \& Forrest 1994, Passalacqua et al. 1999, Battistella-Patterson et al. 2000, Chen et al. 2004). The striking presence of phosphorylated PKCs in meiotic-spindle poles and in the central portion of the elongating meiotic spindle as revealed in our study, together with previous reports, suggest a functional role for PKC phosphorylation in spindle organization and stabilization as well as cytokinesis during mouse oocyte meiosis.

PKC is activated in the nucleus during the $\mathrm{G}_{2}$ phase of the cell cycle, where it is required for mitosis. The PKC $\alpha$ isoform translocated to the nucleus and is found not only associated with the nuclear envelope but mainly with the interchromatin domains (Zini et al. 1995). PKCßII, a mitotic lamin kinase (lamin is a PKC-binding protein), has been shown previously to translocate to the nucleus at the $\mathrm{G}_{2} / \mathrm{M}$ stage and this was coupled to the generation of nuclear diacylglycerol (Sun et al. 1997, Deacon et al. 2002). In fertilized sea-urchin egg cytoplasmic extract, male pronuclear formation is initiated by the disassembly of the sperm nuclear lamina as a result of lamin phosphorylation by a cytosolic PKC (Collas et al. 1997). In our experiment, when the formation of pronucleus occurred, phospho-PKC was concentrated in the pronucleus except for the nucleolus region. Phospho-PKC had no special distribution pattern after nuclear-envelope breakdown and was localized on the entire metaphase spindle of a onecell embryo. Phospho-PKC was also found to localize in the nucleus in early cleavage. The localization of phospho-PKC (pan) in pronuclei of fertilized eggs, nuclei of early mitotic embryo cells, and mitotic spindles suggest that PKC activation may regulate nuclear function and mitotic-spindle assembly in fertilized eggs and early embryos. Identifying potential target substrates and signal network for phospho-PKC will be key in helping to define its function(s) in mammalian early development.

Taken together, the unique distribution pattern of phosphorylated PKC implies possible roles of this family of kinases in regulating microtubule organization and stabilization, nuclear function and cytokinesis during mouse oocyte meiosis, fertilization, and early embryonic mitosis.

\section{Acknowledgements}

This study was supported by grants from the National Natural Science Foundation of China (nos 30225010, 30170358, and 30430530), and Special Funds for Major State Basic Research ('973') Project of China (no. G1999055902).

\section{References}

Battistella-Patterson AS, Fultz ME, Li C, Geng W, Norton M \& Wright GL 2000 PKCalpha translocation is microtubule-dependent in passaged smooth muscle cells. Acta Physiologica Scandinavica $17087-97$. 
Bornslaeger EA, Poueymirou WT, Mattei P \& Schultz RM 1986 Effects of protein kinase $\mathrm{C}$ activators on germinal vesicle breakdown and polar body emission of mouse oocytes. Experimental Cell Research 165 507-517.

Boulikas T 1995 Phosphorylation of transcription factors and control of the cell cycle. Critical Reviews in Eukaryotic Gene Expression 5 $1-77$.

Chen D, Purohit A, Halilovic E, Doxsey SJ \& Newton AC 2004 Centrosomal anchoring of protein kinase $\mathrm{C}$ beta II by pericentrin controls microtubule organization, spindle function, and cytokinesis. Journal of Biological Chemistry 279 4829-4839.

Collas P 1998 Cytoplasmic control of nuclear assembly 1998. Reproduction Fertility and Development 10 581-592.

Collas P, Thompson L, Fields AP, Poccia DL \& Courvalin JC 1997 Protein kinase C-mediated interphase lamin B phosphorylation and solubilization. Journal of Biological Chemistry 272 21274-21280.

Colonna R, Tatone C, Francione A, Rosati F, Callaini G, Corda D \& Di Francesco L 1997 Protein kinase $C$ is required for the disappearance of MPF upon artificial activation in mouse eggs. Molecular Reproduction and Development 48 292-299.

Deacon EM, Pettitt TR, Webb P, Cross T, Chahal H, Wakelam MJ \& Lord JM 2002 Generation of diacylglycerol molecular species through the cell cycle: a role for 1-stearoyl, 2-arachidonyl glycerol in the activation of nuclear protein kinase C-betall at G2/M. Journal of Cell Science 115 983-989.

Downs SM, Cottom J \& Hunzicker-Dunn M 2001 Protein kinase C and meiotic regulation in isolated mouse oocytes. Molecular Reproduction and Development 58 101-115.

Eliyahu E \& Shalgi RA 2002 A role for protein kinase C during rat egg activation. Biology of Reproduction 67 189-195.

Fan H \& Sun QY 2004 Involvement of MAPK cascade during oocyte maturation and fertilization in mammals. Biology of Reproduction $70535-547$.

Fan HY, Tong C, Li MY, Lian L, Chen DY, Schatten H \& Sun QY 2002 Translocation of the classic protein kinase $\mathrm{C}$ isoforms in porcine oocytes: implications of protein kinase $\mathrm{C}$ involvement in the regulation of nuclear activity and cortical granule exocytosis. Experimental Cell Research 277 183-191.

Gallicano GI, McGaughey RW \& Capco DG 1997 Activation of protein kinase $\mathrm{C}$ after fertilization is required for remodeling the mouse egg into the zygote. Molecular Reproduction and Development 46 587-601.

Gangeswaran R \& Jones KT 1997 Unique protein kinase C profile in mouse oocytes: lack of calcium-dependent conventional isoforms suggested by rtPCR and Western blotting. FEBS Letters $\mathbf{4 1}$ 309-312.

LeFevre B, Pesty A, Koziak K \& Testart J 1992 Protein kinase C modulators influence meiosis kinetics but not fertilizability of mouse oocytes. Journal of Experimental Zoology 264 206-213.

Lehrich RW \& Forrest JN Jr 1994 Protein kinase C zeta is associated with the mitotic apparatus in primary cell cultures of the shark rectal gland. Journal of Biological Chemistry 269 32446-32450.
Luria A, Tennenbaum T, Sun QY, Rubinstein S \& Breitbart H 2000 Differential localization of conventional protein kinase $C$ isoforms during mouse oocyte development. Biology of Reproduction 62 1564-1570.

Mellor H \& Parker PJ 1998 The extended protein kinase C superfamily. Biochemical Journal 332 281-292.

Page Baluch D, Koeneman BA, Hatch KR, McGaughey RW \& Capco DG 2004 PKC isotypes in post-activated and fertilized mouse eggs: association with the meiotic spindle. Devlopmental Biology 274 45-55.

Passalacqua M, Patrone M, Sparatore B, Melloni E \& Pontremoli S 1999 Protein kinase C-theta is specifically localized on centrosomes and kinetochores in mitotic cells. Biochemical Journal $\mathbf{3 3 7}$ 113-118.

Quan HM, Fen HY, Meng XQ, Huo LJ, Chen DY, Scahtten H \& Sun QY 2003 Effect of protein kinase C activation on mouse oocyte meiotic maturation, fertilization and early embryo development. Zygote 11 329-337.

Raz T, Eliyahu E, Yesodi V \& Shalgi R 1998 Profile of protein kinase $\mathrm{C}$ isozymes and their possible role in mammalian egg activation. FEBS Letters 431 415-418.

Sun B, Murray NR \& Fields AP 1997 A role for nuclear phosphatidylinositol-specific phospholipase $C$ in the G2/M phase transition. Journal of Biological Chemistry 272 26313-26317.

Sun QY, Rubinstein S \& Breitbart H 1999 MAP kinase activity is downregulated by phorbol ester during mouse oocyte maturation and egg activation in vitro. Molecular Reproduction and Development 52 310-318.

Ventura C \& Maioli M 2001 Protein kinase C control of gene expression. Critical Reviews in Eukaryotic Gene Expression 11 $243-267$.

Viveiros MM, Hirao Y \& Eppig J 2001 Evidence that protein kinase C (PKC) participates in the meiosis I to meiosis II transition in mouse oocytes. Developmental Biology 235 330-342.

Viveiros MM, O'Brien M, Wigglesworth K \& Eppig JJ 2003 Characterization of protein kinase C-delta in mouse oocytes throughout meiotic maturation and following egg activation. Biology of Reproduction 69 1494-1499.

Viveiros MM, O'Brien M \& Eppig JJ 2004 Protein kinase C activity regulates the onset of anaphase I in mouse oocytes. Biology of Reproduction 77 1525-1532.

Voronina E \& Wessel GM 2003 The regulation of oocyte maturation. Current Topics in Developmental Biology 58 53-110.

Zini N, Martelli AM, Neri LM, Bavelloni A, Sabatelli P, Santi S \& Maraldi NM 1995 Immunocytochemical evaluation of protein kinase $\mathrm{C}$ translocation to the inner nuclear matrix in 3T3 mouse fibroblasts after IGF-I treatment. Histochemistry and Cell Biology $103447-457$.

Received 28 May 2004

First decision 19 July 2004

Revised manuscript received 29 September 2004

Accepted 4 November 2004 